$\begin{array}{ll}\text { Research Square } & \begin{array}{l}\text { Preprints are preliminary reports that have not undergone peer review. } \\ \text { They should not be considered conclusive, used to inform clinical practice, } \\ \text { or referenced by the media as validated information. }\end{array}\end{array}$

\title{
Effect of Dexmedetomidine For Thoracoscopic Surgery: A Meta-analysis of Randomized Controlled Trials
}

Chengjun Song ( $\nabla$ yb6239@163.com)

fenghua people hospital

Quan Lu

fenghua people hospital

Research article

Keywords: dexmedetomidine, thoracoscopic surgery, analgesic efficacy, randomized controlled trials

Posted Date: June 29th, 2021

DOI: https://doi.org/10.21203/rs.3.rs-637155/v1

License: () (7) This work is licensed under a Creative Commons Attribution 4.0 International License. Read Full License 


\section{Abstract}

Introduction: The efficacy of dexmedetomidine for thoracoscopic surgery remains controversial. We conduct a systematic review and meta-analysis to explore the impact of dexmedetomidine for thoracoscopic surgery.

Methods: We have searched PubMed, EMbase, Web of science, EBSCO, and Cochrane library databases through September 2020 for randomized controlled trials (RCTs) assessing the effect of dexmedetomidine on thoracoscopic surgery. This meta-analysis is performed using the random-effect model.

Results: Six RCTs involving 510 patients are included in the meta-analysis. Overall, compared with control group for thoracoscopic surgery, dexmedetomidine results in significantly reduced pain scores ( $S M D=-1.50 ; 95 \% \mathrm{Cl}=-2.63$ to $-0.37 ; \mathrm{P}=0.009)$, anesthetic consumption $(\mathrm{SMD}=-3.91 ; 95 \% \mathrm{Cl}=-6.76$ to $-1.05 ; \mathrm{P}=0.007)$, mean heart rate $(S M D=-0.41 ; 95 \% \mathrm{Cl}=-0.65$ to $-0.18 ; \mathrm{P}=0.0007)$, and the number of $\mathrm{ICU}$ stay ( $\mathrm{RR}=0.39 ; 95 \% \mathrm{Cl}=0.19$ to $0.80 ; \mathrm{P}=0.01)$, but showed no obvious effect on mean blood pressure $(S M D=-0.07 ; 95 \% \mathrm{Cl}=-0.45$ to $0.31 ; \mathrm{P}=0.72)$ or hospital stay $(\mathrm{SMD}=-0.61 ; 95 \% \mathrm{Cl}=-1.30$ to $0.08 ; \mathrm{P}=0.08)$.

Conclusions: Dexmedetomidine supplementation can substantially improve the analgesic efficacy for thoracoscopic surgery.

\section{Introduction}

Thoracoscopic surgery is widely used to treat various diseases such as esophageal cancer and lung cancer. It results the smaller incision, less pain and inflammatory response, reduced recovery times compared to traditional surgery [1-3]. The pain commonly occurs after the surgery, and negatively affects the postoperative recovery. Various analgesic regimens have developed for the pain management after thoracoscopic surgery, and they mainly include pharmacologic and regional interventions (e.g. nerve block) [4-7].

Dexmedetomidine, a short-acting a2 -adrenoceptor agonist, is reported to provide the sedation and analgesia for various surgeries [8, 9]. Studies demonstrated that dexmedetomidine attenuated surgical stress responses in patients undergoing surgery, and is effective and safe to improve the analgesic efficacy when serving as an adjunctive analgesic $[10,11]$. Previous trials demonstrated that dexmedetomidine had opioid-sparing properties, maximized pain relief and minimized analgesic-related side effects [12-14].

However, the efficacy of dexmedetomidine supplementation for thoracoscopic surgery has not been well established. Recently, several studies on the topic have been published, and the results were conflicting [7, 15-17]. With accumulating evidence, we therefore perform a systematic review and meta-analysis of RCTs to investigate the analgesic efficacy of dexmedetomidine supplementation for thoracoscopic surgery.

\section{Materials And Methods}

Ethical approval and patient consent are not required because this is a systematic review and meta-analysis of previously published studies. The systematic review and meta-analysis are conducted and reported in adherence to PRISMA (Preferred Reporting Items for Systematic Reviews and Meta-Analyses) [18].

\section{Search strategy and study selection}

Two investigators have independently searched the following databases (inception to September 2020): PubMed, EMbase, Web of science, EBSCO, and Cochrane library databases. The electronic search strategy was conducted using the following keywords: "dexmedetomidine", and "thoracoscopic" or "thoracoscopy". We also check the reference lists of the screened full-text studies to identify other potentially eligible trials.

The inclusive selection criteria are as follows: (i) patients underwent thoracoscopic surgery; (ii) intervention treatments were intravenous dexmedetomidine versus placebo; (iii) study design was RCT.

\section{Data extraction and outcome measures}

We have extracted the following information: author, number of patients, age, male, body mass index, American Society of Anesthesiologists (ASA) and detail methods in each group etc. Data were extracted independently by two investigators, and discrepancies are resolved by consensus. We also contacted the corresponding author to obtain the data when necessary.

The primary outcome was pain scores. Secondary outcomes included analgesic consumption, mean heart rate and blood pressure, ICU stay, and hospital stay.

\section{Quality assessment in individual studies}

Methodological quality of the included studies is independently evaluated using the modified Jadad scale [19]. There are 3 items for Jadad scale: randomization (0-2 points), blinding (0-2 points), dropouts and withdrawals (0-1 points). The score of Jadad Scale varies from 0 to 5 points. An article with Jadad score $\leq 2$ is considered to be of low quality. If the Jadad score $\geq 3$, the study is thought to be of high quality [20].

\section{Statistical analysis}

We estimate the standard mean difference (SMD) with 95\% confidence interval (Cl) for continuous outcomes (pain scores, analgesic consumption, mean heart rate and blood pressure, and hospital stay) and relative risk (RR) with 95\% $\mathrm{Cl}$ for dichotomous outcomes (ICU stay). The random-effects model was used regardless of heterogeneity. Heterogeneity was reported using the $\mathrm{I}^{2}$ statistic, and $\mathrm{I}^{2}>50 \%$ indicated significant heterogeneity [21]. Whenever significant heterogeneity was present, we searched for potential sources of heterogeneity via omitting one study in turn for the meta-analysis or performing subgroup 
analysis. Publication bias was not evaluated because of the limited number $(<10)$ of included studies. All statistical analyses were performed using Review Manager Version 5.3 (The Cochrane Collaboration, Software Update, Oxford, UK).

\section{Results}

\section{Literature search, study characteristics and quality assessment}

A detailed flowchart of the search and selection results was shown in Figure 1. 239 potentially relevant articles are identified initially. Finally, six RCTs that meet our inclusion criteria are included in the meta-analysis $[7,15-17,22,23]$.

The baseline characteristics of the six eligible RCTs in the meta-analysis were summarized in Table 1 . The six studies were published between 2016 and 2020 , and the total sample size was 510. Dexmedetomidine was used before the anesthesia [7, 15, 22, 23], or during surgery [16, 17].

Among the six studies included here, three studies reported pain scores [15, 16, 22], three studies reported analgesic consumption [7, 16, 22], four studies reported mean heart rate and blood pressure $[7,15,17,22]$, three studies reported ICU stay $[15,17,23]$, and three studies reported hospital stay $[17,22,23]$. Jadad scores of the six included studies vary from 3 to 5 , and all six studies are considered to be high-quality ones according to quality assessment.

\section{Primary outcome: pain scores}

This outcome data was analyzed with the random-effects model, and the pooled estimate of the three included RCTs suggested that compared to control group for thoracoscopic surgery, dexmedetomidine was associated with significantly reduced pain scores $(\mathrm{SMD}=-1.50 ; 95 \% \mathrm{Cl}=-2.63$ to -0.37 ; $\mathrm{P}=0.009)$, with significant heterogeneity among the studies $\left(\mathrm{I}^{2}=95 \%\right.$, heterogeneity $\left.\mathrm{P}<0.00001\right)$ (Figure 2$)$.

\section{Sensitivity analysis}

Significant heterogeneity is observed among the included studies for the primary outcomes, but there is still significant heterogeneity after when performing sensitivity analysis via omitting one study in turn to detect the heterogeneity.

\section{Secondary outcomes}

Compared to control group for thoracoscopic surgery, dexmedetomidine can significantly reduce anesthetic consumption (SMD=-3.91; $95 \% \mathrm{Cl}=-6.76$ to -1.05 ; $\mathrm{P}=0.007$; Figure 3$)$ and mean heart rate $(\mathrm{SMD}=-0.41 ; 95 \% \mathrm{Cl}=-0.65$ to $-0.18 ; \mathrm{P}=0.0007$; Figure 4$)$, but has no important impact on mean blood pressure $(\mathrm{SMD}=-0.07 ; 95 \% \mathrm{Cl}=-0.45$ to $0.31 ; \mathrm{P}=0.72$; Figure 5). In addition, dexmedetomidine was associated with the decrease in the number of ICU stay (RR=0.39; $95 \%$ $\mathrm{Cl}=0.19$ to $0.80 ; \mathrm{P}=0.01$; Figure 6$)$, but revealed no effect on hospital stay ( $\mathrm{SMD}=-0.61 ; 95 \% \mathrm{Cl}=-1.30$ to $0.08 ; \mathrm{P}=0.08$; Figure 7$)$.

\section{Discussion}

Thoracoscopic surgery has been widely used to treat lung cancer because of its minimally invasion, less postoperative pain and shortened hospital stay compared with open thoracotomy [24]. Postoperative pain management, particularly early postoperative pain, still remains a matter of concern for many anesthesiologists and these patients $[25,26]$. Opioids are essential during surgery, and many methods are developed to reduce opioid consumption due to the side effects such as delayed recovery from general anesthesia, opioid-induced nausea, and respiratory depression [27, 28].

Intraoperative dexmedetomidine was reported to improve the effects of postoperative analgesia [29-31]. It showed analgesic, sedative and anxiolytic effects, and avoided respiratory depression and the inhibitory effect of sympathetic stimulation as an adjunct to general anesthesia [8]. Our meta-analysis included six RCTs and 510 patients. The results revealed that intravenous dexmedetomidine was associated with substantially reduced pain scores, anesthetic consumption, the number of ICU stay and mean heart rate after thoracoscopic surgery, but showed no obvious influence on mean blood pressure or hospital stay.

In addition, dexmedetomidine benefited to maintain the stability of the cardiovascular system and decrease the stress response [10]. Intraoperative infusion of dexmedetomidine decreased both norepinephrine and epinephrine. Dexmedetomidine can decrease the release of catecholamines and has analgesic, anxiolytic, and hypnotic effects [32]. Regarding the sensitivity analysis, there is significant heterogeneity. Several reasons may account for the heterogeneity. Firstly, different doses and methods of dexmedetomidine supplementation may produce some bias. For instance, Dexmedetomidine was used before the anesthesia $[7,15,22,23]$ or during surgery $[16,17]$. Secondly, dexmedetomidine was applied as the adjunct to different drugs such as oxycodone and sevoflurane, which may result in various analgesic effect. Thirdly, different operation procedures produces various pain intensity, which may affect the pooling results.

This meta-analysis has several potential limitations. Firstly, our analysis is based on only six RCTs, and three of them have a relatively small sample size $(n<100)$. Overestimation of the treatment effect was more likely in smaller trials compared with larger samples. Next, the doses, methods and combination of anesthetic drugs in included RCTs are different, which may have an influence on the pooling results. Finally, thoracoscopic surgeries are performed for various diseases and operation procedures.

\section{Conclusions}

Dexmedetomidine benefits to improve the analgesic efficacy for thoracoscopic surgery. 


\section{Abbreviations}

randomized controlled trials: RCTs

mean differences: MDs

confidence intervals: Cls

risk ratios: RRs

\section{Declarations}

\section{Ethical Approval and Consent to participate}

Not applicable.

\section{Consent for publication}

Not applicable.

Availability of supporting data

Not applicable.

Competing interests

The authors declare no conflict of interest.

\section{Funding}

Not applicable.

Authors' contributions

Chengjun Song conducted the design, study planning, data analysis and data interpretation. Quan Lu wrote and revised the article. All authors read and approved the final manuscript.

\section{Acknowledgements}

None.

\section{References}

[1] T. Murakawa, H. Sato, S. Okumura, J. Nakajima, H. Horio, Y. Ozeki, H. Asamura, N. Ikeda, H. Otsuka, H. Matsuguma, I. Yoshino, M. Chida, M. Nakayama, T. lizasa, M. Okumura, S. Shiono, R. Kato, T. lida, N. Matsutani, M. Kawamura, Y. Sakao, K. Funai, G. Furuyashiki, H. Akiyama, S. Sugiyama, N. Kanauchi, Y. Shiraishi, J. Metastatic Lung Tumor Study Group of, Thoracoscopic surgery versus open surgery for lung metastases of colorectal cancer: a multi-institutional retrospective analysis using propensity score adjustmentdagger, European journal of cardio-thoracic surgery : official journal of the European Association for Cardio-thoracic Surgery 51(6) (2017) 1157-1163.

[2] Y. 20466101 Kinjo, N. Kurita, F. Nakamura, H. Okabe, E. Tanaka, Y. Kataoka, A. Itami, Y. Sakai, S. Fukuhara, Effectiveness of combined thoracoscopiclaparoscopic esophagectomy: comparison of postoperative complications and midterm oncological outcomes in patients with esophageal cancer, Surgical endoscopy 26(2) (2012) 381-90.

[3] T.H. Pham, K.A. Perry, J.P. Dolan, P. Schipper, M. Sukumar, B.C. Sheppard, J.G. Hunter, Comparison of perioperative outcomes after combined thoracoscopiclaparoscopic esophagectomy and open Ivor-Lewis esophagectomy, American journal of surgery 199(5) (2010) 594-8.

[4] R.G. Davies, P.S. Myles, J.M. Graham, A comparison of the analgesic efficacy and side-effects of paravertebral vs epidural blockade for thoracotomy-a systematic review and meta-analysis of randomized trials, British journal of anaesthesia 96(4) (2006) 418-26.

[5] J.F. Sztain, R.A. Gabriel, E.T. Said, Thoracic Epidurals are Associated With Decreased Opioid Consumption Compared to Surgical Infiltration of Liposomal Bupivacaine Following Video-Assisted Thoracoscopic Surgery for Lobectomy: A Retrospective Cohort Analysis, Journal of cardiothoracic and vascular anesthesia (2018).

[6] S.D. Adhikary, A. Pruett, M. Forero, V. Thiruvenkatarajan, Erector spinae plane block as an alternative to epidural analgesia for post-operative analgesia following video-assisted thoracoscopic surgery: A case study and a literature review on the spread of local anaesthetic in the erector spinae plane, Indian journal of anaesthesia 62(1) (2018) 75-78.

[7] X. Wang, K. Wang, B. Wang, T. Jiang, Z. Xu, F. Wang, J. Yu, Effect of Oxycodone Combined With Dexmedetomidine for Intravenous Patient-Controlled Analgesia After Video-Assisted Thoracoscopic Lobectomy, Journal of cardiothoracic and vascular anesthesia 30(4) (2016) $1015-21$.

[8] D.S. Carollo, B.D. Nossaman, U. Ramadhyani, Dexmedetomidine: a review of clinical applications, Current opinion in anaesthesiology 21 (4) (2008) 457-61. 
[9] R.M. Venn, C.J. Bradshaw, R. Spencer, D. Brealey, E. Caudwell, C. Naughton, A. Vedio, M. Singer, R. Feneck, D. Treacher, S.M. Willatts, R.M. Grounds, Preliminary UK experience of dexmedetomidine, a novel agent for postoperative sedation in the intensive care unit, Anaesthesia 54(12) (1999) 1136-42.

[10] M.H. Kim, K.Y. Lee, S.J. Bae, M. Jo, J.S. Cho, Intraoperative dexmedetomidine attenuates stress responses in patients undergoing major spine surgery, Minerva anestesiologica 85(5) (2019) 468-477.

[11] R. Shamim, S. Srivastava, A. Rastogi, K. Kishore, A. Srivastava, Effect of Two Different Doses of Dexmedetomidine on Stress Response in Laparoscopic Pyeloplasty: A Randomized Prospective Controlled Study, Anesthesia, essays and researches 11(4) (2017) 1030-1034.

[12] H.C. Kim, Y.H. Lee, Y.T. Jeon, J.W. Hwang, Y.J. Lim, J.E. Park, H.P. Park, The effect of intraoperative dexmedetomidine on postoperative catheter-related bladder discomfort in patients undergoing transurethral bladder tumour resection: A double-blind randomised study, European journal of anaesthesiology 32(9) (2015) 596-601.

[13] P. Shorrock, T. Heaton, N. Cochrane, M. Jackson, K. Lund, N. Plummer, The effects of dexmedetomidine on postoperative pain, Anaesthesia 70(3) (2015) 372.

[14] K. Peng, H.Y. Liu, S.R. Wu, H. Cheng, F.H. Ji, Effects of Combining Dexmedetomidine and Opioids for Postoperative Intravenous Patient-controlled Analgesia: A Systematic Review and Meta-analysis, The Clinical journal of pain 31(12) (2015) 1097-104.

[15] Y.L. Wang, X.Q. Kong, F.H. Ji, Effect of dexmedetomidine on intraoperative Surgical Pleth Index in patients undergoing video-assisted thoracoscopic lung lobectomy, Journal of cardiothoracic surgery 15(1) (2020) 296.

[16] J.A. Kim, H.J. Ahn, M. Yang, S.H. Lee, H. Jeong, B.G. Seong, Intraoperative use of dexmedetomidine for the prevention of emergence agitation and postoperative delirium in thoracic surgery: a randomized-controlled trial, Canadian journal of anaesthesia = Journal canadien d'anesthesie 66(4) (2019) 371379 .

[17] C.Y. Wu, Y.F. Lu, M.L. Wang, J.S. Chen, Y.C. Hsu, F.S. Yang, Y.J. Cheng, Effects of Dexmedetomidine Infusion on Inflammatory Responses and Injury of Lung Tidal Volume Changes during One-Lung Ventilation in Thoracoscopic Surgery: A Randomized Controlled Trial, Mediators of inflammation 2018 (2018) 2575910.

[18] D. Moher, A. Liberati, J. Tetzlaff, D.G. Altman, P. Group, Preferred reporting items for systematic reviews and meta-analyses: the PRISMA statement, Journal of clinical epidemiology 62(10) (2009) 1006-12.

[19] A.R. Jadad, R.A. Moore, D. Carroll, C. Jenkinson, D.J.M. Reynolds, D.J. Gavaghan, H.J. McQuay, Assessing the quality of reports of randomized clinical trials: Is blinding necessary?, Controlled Clinical Trials 17(1) (1996) 1-12.

[20] L.L. Kjaergard, J. Villumsen, C. Gluud, Reported Methodologic Quality and Discrepancies between Large and Small Randomized Trials in Meta-Analyses, Annals of Internal Medicine 135(11) (2001) 982-989.

[21] J.P. Higgins, S.G. Thompson, Quantifying heterogeneity in a meta-analysis, Statistics in medicine 21(11) (2002) $1539-58$.

[22] S.H. Lee, C.Y. Lee, J.G. Lee, N. Kim, H.M. Lee, Y.J. Oh, Intraoperative Dexmedetomidine Improves the Quality of Recovery and Postoperative Pulmonary Function in Patients Undergoing Video-assisted Thoracoscopic Surgery: A CONSORT-Prospective, Randomized, Controlled Trial, Medicine 95(7) (2016) e2854.

[23] S.H. Lee, N. Kim, C.Y. Lee, M.G. Ban, Y.J. Oh, Effects of dexmedetomidine on oxygenation and lung mechanics in patients with moderate chronic obstructive pulmonary disease undergoing lung cancer surgery: A randomised double-blinded trial, European journal of anaesthesiology 33(4) (2016) 275-82.

[24] K.J. Steinthorsdottir, L. Wildgaard, H.J. Hansen, R.H. Petersen, K. Wildgaard, Regional analgesia for video-assisted thoracic surgery: a systematic review, European journal of cardio-thoracic surgery : official journal of the European Association for Cardio-thoracic Surgery 45(6) (2014) 959-66.

[25] P.E. Falcoz, M. Puyraveau, P.A. Thomas, H. Decaluwe, M. Hürtgen, R.H. Petersen, H. Hansen, A. Brunelli, Video-assisted thoracoscopic surgery versus open lobectomy for primary non-small-cell lung cancer: a propensity-matched analysis of outcome from the European Society of Thoracic Surgeon database, European journal of cardio-thoracic surgery : official journal of the European Association for Cardio-thoracic Surgery 49(2) (2016) 602-9.

[26] M. Bendixen, O.D. Jørgensen, C. Kronborg, C. Andersen, P.B. Licht, Postoperative pain and quality of life after lobectomy via video-assisted thoracoscopic surgery or anterolateral thoracotomy for early stage lung cancer: a randomised controlled trial, The Lancet. Oncology 17(6) (2016) 836-844.

[27] H. Clarke, N. Soneji, D.T. Ko, L. Yun, D.N. Wijeysundera, Rates and risk factors for prolonged opioid use after major surgery: population based cohort study, BMJ (Clinical research ed.) 348 (2014) g1251.

[28] D. Fletcher, V. Martinez, Opioid-induced hyperalgesia in patients after surgery: a systematic review and a meta-analysis, British journal of anaesthesia 112(6) (2014) 991-1004.

[29] S. Grape, K.R. Kirkham, J. Frauenknecht, E. Albrecht, Intra-operative analgesia with remifentanil vs. dexmedetomidine: a systematic review and metaanalysis with trial sequential analysis, Anaesthesia 74(6) (2019) 793-800. 
[30] P. Ranganathan, M.K. Ritchie, M.B. Ellison, A. Petrone, P. Heiraty, L.E. Tabone, A randomized control trial using intraoperative dexmedetomidine during Roux-en-Y gastric bypass surgery to reduce postoperative pain and narcotic use, Surgery for obesity and related diseases : official journal of the American Society for Bariatric Surgery 15(4) (2019) 588-594.

[31] M.M. Beder El Baz, T.E.M. Farahat, Intraperitoneal Levobupivacaine Alone or with Dexmedetomidine for Postoperative Analgesia after Laparoscopic Cholecystectomy, Anesthesia, essays and researches 12(2) (2018) 355-358.

[32] R. Gertler, H.C. Brown, D.H. Mitchell, E.N. Silvius, Dexmedetomidine: a novel sedative-analgesic agent, Proceedings (Baylor University. Medical Center) 14(1) (2001) 13-21.

\section{Tables}

Table 1 Characteristics of included studies

NO. Author Dexmedetomidine group Control group

\begin{tabular}{|c|c|c|c|c|c|c|c|c|c|c|c|c|}
\hline & & Number & Age (years) & $\begin{array}{l}\text { Male } \\
(n)\end{array}$ & $\begin{array}{l}\text { Body mass } \\
\text { index } \\
(\mathrm{kg} / \mathrm{m} 2)\end{array}$ & $\begin{array}{l}\text { ASA } \\
(\mathrm{I} / \mathrm{II} / \mathrm{III})\end{array}$ & Methods & Number & Age (years) & $\begin{array}{l}\text { Male } \\
(n)\end{array}$ & $\begin{array}{l}\text { Body mass } \\
\text { index } \\
(\mathrm{kg} / \mathrm{m} 2)\end{array}$ & $\begin{array}{l}\text { ASA } \\
(1 / 11 / 1\end{array}$ \\
\hline 1 & $\begin{array}{l}\text { Wang } \\
2020\end{array}$ & 46 & $56.78 \pm 12.81$ & 17 & $22.09 \pm 3.22$ & $7 / 39 / 0$ & $\begin{array}{l}\text { dexmedetomidine } \\
0.8 \mu \mathrm{g} / \mathrm{kg} \\
\text { administered for } \\
10 \mathrm{~min} \text { before } \\
\text { anesthesia }\end{array}$ & 44 & $60.48 \pm 12.58$ & 22 & $22.89 \pm 2.85$ & 10/3، \\
\hline 2 & $\begin{array}{l}\text { Kim } \\
2019\end{array}$ & 60 & $\begin{array}{l}63 \text { [58-68], } \\
\text { median } \\
\text { [interquartile } \\
\text { range] }\end{array}$ & 28 & $24 \pm 3$ & $18 / 42 / 0$ & $\begin{array}{l}\text { dexmedetomidine } \\
\text { started after } \\
\text { inducing } \\
\text { anesthesia and } \\
\text { continued until } \\
\text { the end of } \\
\text { surgery at a fixed } \\
\text { dose }(0.5 \\
\text { ug } / \mathrm{kg} / \mathrm{h})\end{array}$ & 60 & 59 [56-65] & 30 & $23 \pm 5$ & $20 / 41$ \\
\hline 3 & $\begin{array}{l}\text { Wu } \\
2018\end{array}$ & 30 & $59.0 \pm 8.8$ & 15 & - & $2 / 14 / 14$ & $\begin{array}{l}0.5 \mathrm{ug} / \mathrm{kg} / \mathrm{h} \\
\text { dexmedetomidine } \\
\text { through the } \\
\text { surgery }\end{array}$ & 30 & $58.7 \pm 10.1$ & 16 & - & 1/18, \\
\hline 4 & $\begin{array}{l}\text { Wang } \\
2016\end{array}$ & 40 & $54.25 \pm 9.98$ & 20 & $21.93 \pm 2.12$ & - & $\begin{array}{l}0.5 \mu \mathrm{g} / \mathrm{kg} \text {, } \\
\text { dexmedetomidine } \\
\text { diluted to } 20 \mathrm{~mL} \\
\text { with physiologic } \\
\text { saline and } \\
\text { infused for } 10 \\
\text { minutes } \\
\text { intravenously } \\
\text { before the } \\
\text { surgery plus } 50 \\
\text { mg of oxycodone }\end{array}$ & 40 & $55.63 \pm 11.20$ & 20 & $22.10 \pm 2.13$ & - \\
\hline 5 & $\begin{array}{l}\text { Lee } \\
2016\end{array}$ & 50 & $62.0 \pm 10.5$ & 26 & $23.6 \pm 0.4$ & $0 / 37 / 13$ & $\begin{array}{l}\text { dexmedetomidine } \\
1.0 \mathrm{ug} / \mathrm{kg} \text { for } 20 \\
\text { minutes before } \\
\text { the termination of } \\
\text { surgery }\end{array}$ & 50 & $62.0 \pm 11.5$ & 23 & $23.6 \pm 0.4$ & $0 / 42$ \\
\hline 6 & $\begin{array}{l}\text { Lee } \\
2016 \\
(2)\end{array}$ & 25 & $68.4 \pm 6.4$ & 12 & $22.3 \pm 2.7$ & $0 / 11 / 14$ & $\begin{array}{l}\text { dexmedetomidine } \\
\text { at an initial } \\
\text { loading dose of } \\
1.0 \mathrm{ug} / \mathrm{kg} \text { over } 10 \\
\text { min followed by a } \\
\text { maintenance } \\
\text { dose of } 0.5 \\
\text { ug/kg/h during } \\
\text { the surgery }\end{array}$ & 25 & $69.4 \pm 8.7$ & 11 & $22.7 \pm 2.1$ & $0 / 12$ \\
\hline
\end{tabular}

American Society of Anesthesiologists (ASA).

\section{Figures}




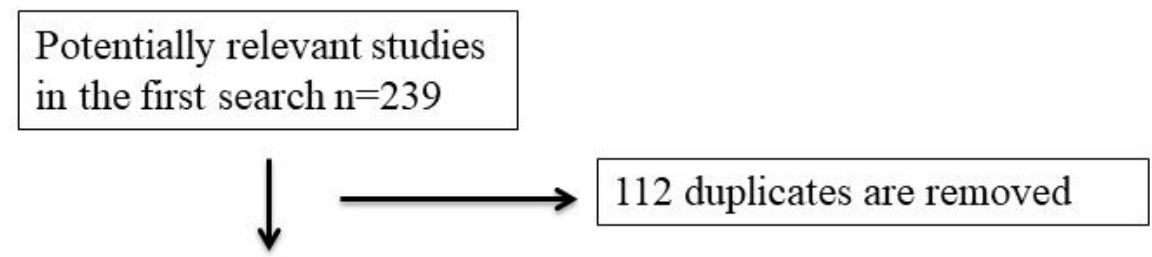

127 initial included

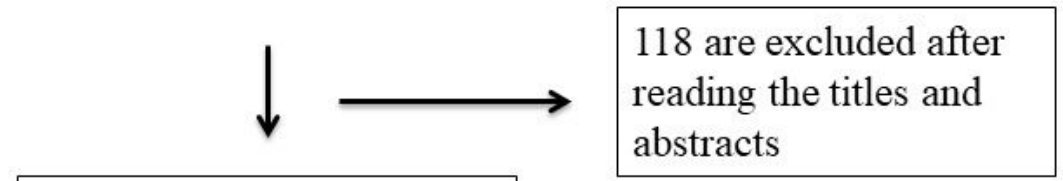

9 full articles assessed for eligibility

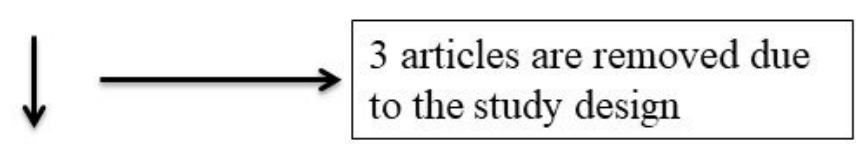

6 articles are included

Figure 1

Flow diagram of study searching and selection process.

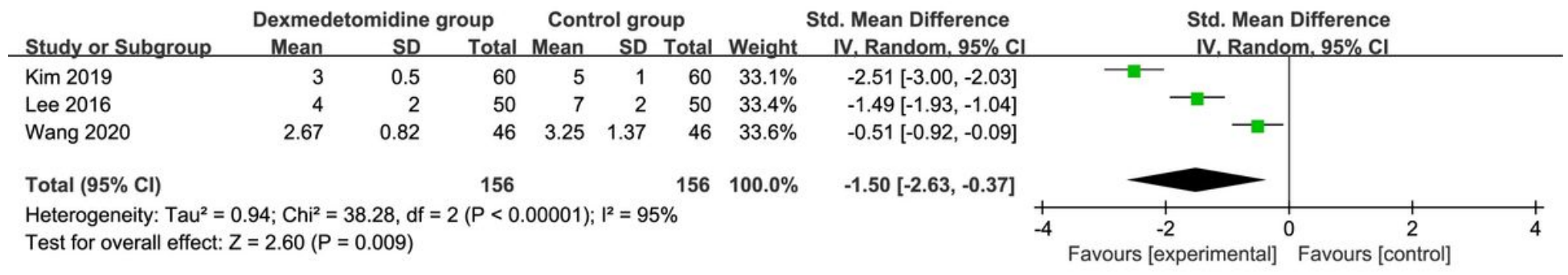

Figure 2

Forest plot for the meta-analysis of pain scores.

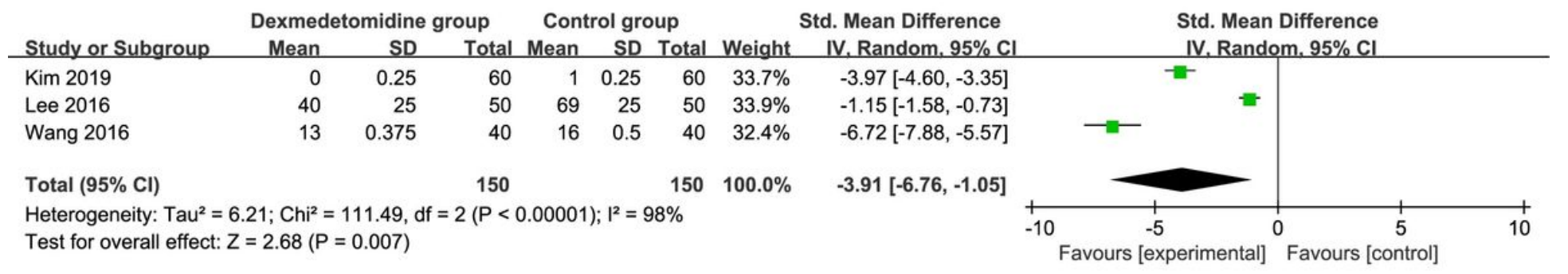

Figure 3

Forest plot for the meta-analysis of analgesic consumption. 


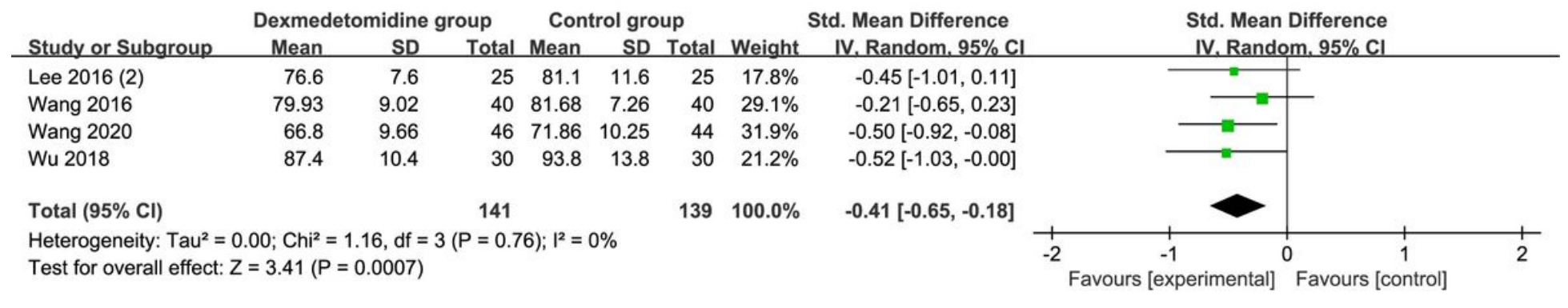

\section{Figure 4}

Forest plot for the meta-analysis of mean heart rate.

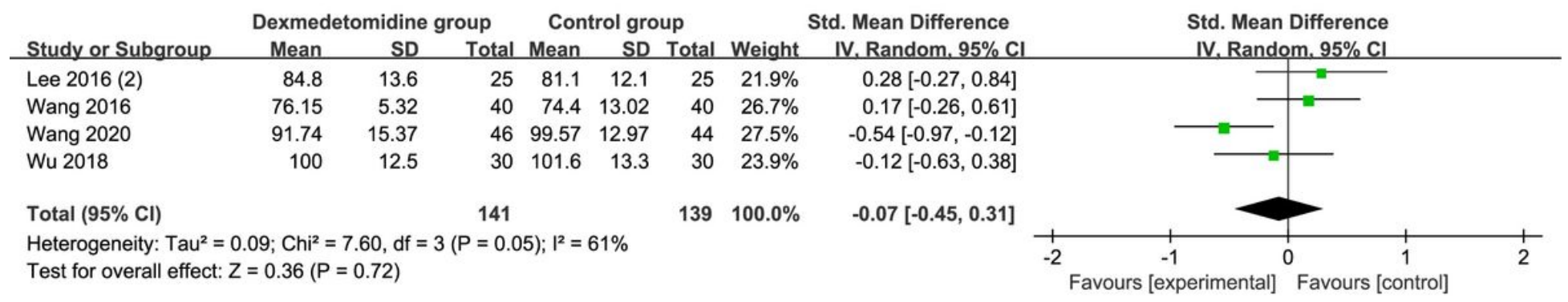

Figure 5

Forest plot for the meta-analysis of mean blood pressure.

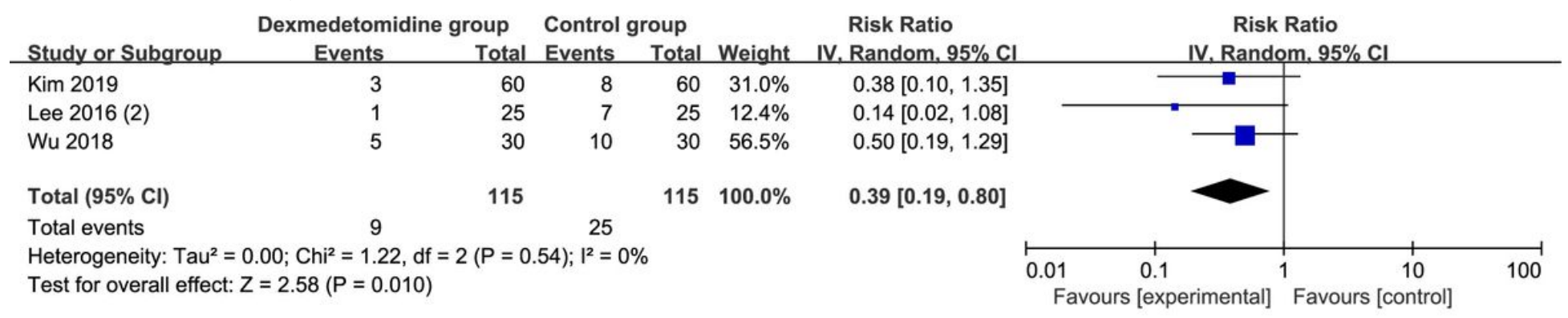

Figure 6

Forest plot for the meta-analysis of ICU stay.

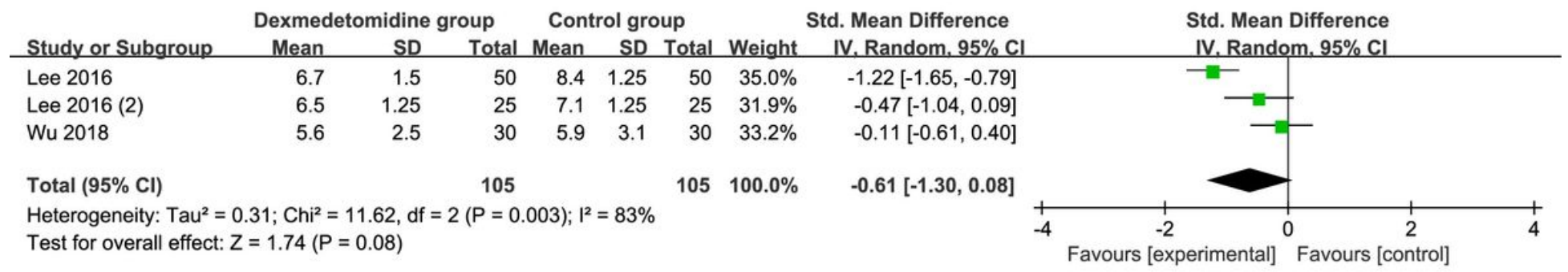

Figure 7

Forest plot for the meta-analysis of hospital stay. 